\title{
Yield of Video Assisted Thoracoscopy in Undiagnosed Pleural Effusions in South Indian Population
}

\author{
Authors

\section{Umar Majid', A. K. Abdul Khader' ${ }^{2}$, C. P. Rouf ${ }^{3}$}

${ }^{1}$ Department of Pulmonology, SKIMS medical college hospital Bemina, Srinagar, Kashmir J\&K INDIA

${ }^{2,3}$ Department of Respiratory Medicine, Chest Hospital, Calicut, Kerela, INDIA

Corresponding Author

Dr M Umar Majid M.D, DNB, FCCP

311C Lane no. 7 Budshah Nagar, Natipora Srinagar Kashmir 190015 J\&K INDIA

Email:drumarmajidrx@yahoo.com

\begin{abstract}
Pleural effusion of unknown etiology is a real diagnostic challenge for clinicians. Up to $75 \%$ of effusions are diagnosed with simple diagnostic thoracentesis but cause of a pleural effusion is not evident following diagnostic thoracentesis in up to 25 percent of patients. Medical thoracoscopy has received renewed interest in the recent past for diagnostic as well as therapeutic uses. In this study, we describe our experience with thoracoscopy for undiagnosed pleural effusions.

Aims and objective: To study the yield of video assisted thoracoscopy in cases of pleural effusion where all the other diagnostic modalities failed to give a definite diagnosis.

Materials and Methods: Analysis of thoracoscopic procedures performed for undiagnosed pleural effusion cases between March 2002 to Feb. 2010 at Chest Hospital.

Yield of thoracoscopic pleural biopsy for achieving a diagnosis in undiagnosed pleural effusions, was evaluated. Complications of thoracoscopy were also analyzed.

Results: A total of 84 patients met the study criteria and were included. Diagnostic yield of Zthoracoscopic pleural biopsy was $100 \%$.

Pleural malignancy was diagnosed in $73.8 \%$ of patients. There were only 4 cases of mesothelioma and the rest were of pleural metastasis. Lung cancer was the most common cause of primary malignancy. Adenocarcinoma being the most common type. Tuberculosis was diagnosed in $26.2 \%$ of patients. No major complications after thoracoscopy were observed. Most common minor complication observed was pain (35.7\%).

Conclusion: Video assisted thoracoscopy is a safe procedure and has excellent diagnostic yield in patients with undiagnosed pleural effusions.

Keywords: Thoracoscopy, pleural effusion, tuberculosis, malignancy
\end{abstract}

\section{INTRODUCTION}

The pleural space is bounded by the parietal and visceral membranes covered by a continuous layer of pleural mesothelial cells. Studies of pleural liquid dynamics in the normal pleural space are limited. Available data indicate that pleural fluid is formed from the systemic vessels of the pleural membranes at an approximate rate of $0.6 \mathrm{ml} / \mathrm{h}$ and 
is absorbed at a similar rate by the parietal pleural lymphatic system. Normally, the pleural spaces contain approximately $0.25 \mathrm{ml} / \mathrm{kg}$ of low protein liquid. Disturbances in either formation or absorption result in the accumulation of excess pleural fluid $^{1-7}$.

Pleural effusion is the abnormal accumulation of fluid in the pleural space. A pleural effusion is always abnormal and indicates the presence of an underlying disease. Despite the fact that there are many causes of pleural effusion, it is estimated that $90 \%$ of all pleural effusions are the result of only 5 disease processes; congestive heart failure, pneumonia, malignancy, pulmonary embolism and viral infection.

- Determining the cause of a pleural effusion is greatly facilitated by analysis of the pleural fluid.

Thoracentesis is a simple bedside procedure that permits fluid to be rapidly sampled, visualized, examined microscopically, and quantified. A systematic approach to analysis of the fluid in conjunction with the clinical presentation should allow the clinician to diagnose the cause of an effusion in about 75 percent of patients at the first encounter. A definitive diagnosis provided by the finding of malignant cells or specific organisms in the pleural fluid, can be established in approximately 25 percent of patients. A presumptive diagnosis, based on the prethoracentesis clinical impression, can be substantiated by pleural fluid analysis in an additional 50 percent of patients.

Pleural effusions can develop as a result of different pleuropulmonary or systemic disorders. The cause of a pleural effusion is not evident following diagnostic thoracentesis in up to 25 percent of patients ${ }^{8}$. Although no universally accepted definition exists for an "undiagnosed effusion," the first step for the clinician is to revisit the patient's history, paying particular attention to drugs, occupational exposures, risk factors for pulmonary embolism or tuberculosis, and comorbid conditions.

Some effusions resolve spontaneously, but the time required for resolution varies depending upon the underlying etiology. Uncomplicated parapneumonic effusions and effusions from pulmonary embolism, tuberculous pleurisy, and postcardiac injury syndrome may persist for several weeks ${ }^{9}$. Malignant pleural effusions, on the other hand, do not resolve spontaneously. Benign asbestos pleural effusion, rheumatoid pleurisy, and radiation pleuritis often persist for months to years. Other effusions that may persist for years include those caused by lymphatic abnormalities (eg, yellow-nail syndrome and pulmonary lymphangiectasia) and trapped lung. ${ }^{10-}$ 11

If clinical examination and pleural fluid analysis fail to result in a diagnosis, additional investigations with imaging and pleural biopsy will be needed. $^{12}$

Pleural biopsy typically follows CT scan in undiagnosed pleural effusions. A number of techniques for pleural biopsy are available. Percutaneous techniques include closed pleural biopsy and CT guided cutting needle biopsy. The former is useful primarily when diseases such as tuberculosis are suspected ${ }^{12}$. CT guided biopsy is useful when a pleural based mass is visible.

Video assisted thoracoscopic pleural biopsy is increasingly used to diagnose malignancy when an obvious mass isn't visible on CT, when percutaneous biopsy is negative, or when patchy disease is suspected ${ }^{13-14 .}$

Thoracoscopy involves a percutaneous approach to placement of an endoscopic instrument within the pleural space, allowing direct visualization and sampling of the pleura. Unlike video-assisted thoracic surgery (VATS), in which the surgeon uses a thoracoscope to assist with performance of minimally invasive surgery, the purpose of "medical thoracoscopy" is to provide access to the pleura and the pleural space for evaluation and, in some cases, management of pleural disease. ${ }^{15-17}$

The rigid thoracoscope is currently the most common instrument used for thoracoscopy, providing both excellent optical quality and maneuverability within the pleural space. Additional instruments that are used in conjunction with the rigid thoracoscope include 
probes for palpation and forceps for coagulation or biopsy. Sclerosing agents may be insufflated into the pleural cavity, either through a working channel within the scope or through a separate puncture site at a different interspace.

The semi-rigid fiberoptic video pleuroscope is becoming now more popular, because of its similarity to the standard flexible bronchoscope makes it easy to use (eg, the handle, suction port, and biopsy port are similar) and the image quality has significantly improved. ${ }^{18-26}$

The major indication for medical thoracoscopy is evaluation of exudative pleural effusions which remain undiagnosed after pleural fluid analysis, where thoracoscopy is suggested as an alternative to closed pleural biopsy.

With thoracoscopy, one can visualize the entire visceral and parietal pleura and take pleural biopsy from suspicious sites under vision.

Although thoracoscopy can be used to visualize pleural blebs and bullae in patients with spontaneous pneumothorax, this is seldom the indication for thoracoscopy. Medical thoracoscopy can be used for therapeutic procedures, such as adhesiolysis and evacuation of pleural fluid in patients with empyema, pleurodesis in patients with malignant pleural effusion and spontaneous pneumothorax.

In the present study, we describe our experience with the technique of medical thoracoscopy in patients who underwent thoracoscopy for diagnostic purposes.

\section{MATERIALS AND METHODS}

This was a retrospective study conducted in the Department of Respiratory Medicine, Chest Hospital, Calicut, between March 2002 to Feb. 2010. Video assisted thoracoscopy was done for 84 patients who met the inclusion criteria, and were therefore selected for study. All patients underwent detailed clinical evaluation before procedure and thoroughly investigated to rule out any procedural contraindication.

Procedure was done under conscious sedation, in lateral decubitus position with diseased side up using intravenous midazolam $(0.5 \mathrm{mg} / \mathrm{kg}$ body
weight).Intravenous tramadol $5 \mathrm{mg}$ was also used for analgesic purpose. Skin, subcutaneous tissue, intercostal muscle and parietal pleura were anesthetised with $2 \%$ lignocaine.

A small incision was given in 5th or 6th intercostal space in mid-axillary line, then blunt dissection of subcutaneous tissue and the intercostal muscles was done and a cannula of $10 \mathrm{~mm}$ diameter with blunt trocar was inserted carefully into the pleural cavity. The trocar was removed and then thoracoscope was introduced. Almost all pleural fluid was drained to have a clear vision of pleural cavity and multiple biopsies were taken from parietal pleura. At the end of the procedure, a 28 to 32 Fr chest tube was put. After the full expansion of the lung with tube drainage of less than $50 \mathrm{~mL}$ per 24 hours, chest tube was removed.

Data regarding gender and age of the patients were analyzed. Age (in years) was defined as that at the time of pleural biopsy. The histopatholgical diagnoses obtained were also analyzed. Regarding the surgical procedure, the variables studied were diagnostic yield, surgical complications, and postoperative complications.

\section{Inclusion criteria}

1. Patients between 25-75 years of age.

2. Clinical and Radiological features suggestive of pleural effusion

3. No documentation of underlying etiology despite all available diagnostic modalities other than VAT.

\section{Exclusion criteria}

1. Pleural effusion with definite underlying etiology.

2. Severe cardiovascular diseases, severe pulmonary dysfunction, advance age or other major risk for surgery or general anesthesia.

3. High likelihood that adequate sized hiopsies from multiple sites will not to be obtained.

4. Patients of age $<25$ or $>75$ years.

5. Pregnant ladies.

Statistical data was analyzed using computer software, Statistical Package for Social Sciences 
(SPSS) version 16, and expressed in its frequency and percentage in descriptive fashion

\section{OBSERVATIONS \& RESULTS \\ Data Analysis}

During the study period, 84 patients $(81 \%$ men and $19 \%$ women; mean age of $54.14+/ 15.87$ years (Mean +/ SD) with undiagnosed pleural effusion underwent thoracoscopy for diagnostic purposes.

Large proportion of Undiagnosed pleural effusion, $62 / 84(73.8 \%)$ proved to be Malignancy followed by Tuberculosis 22/84 (26.2\%).
Total numbers of malignant effusions were 62 out of which $(80.64 \%)$ were males and $(19.35 \%)$ were females. Total numbers of tuberculous effusions were 22 out which $(81.81 \%)$ were males and (18.18\%) were females.

\section{Distribution of Malignancies}

Most common cause of malignant effusion was pleural metastasis. Among the patients with metastatic pleural malignancy, the most common site of primary malignancy was the lung.

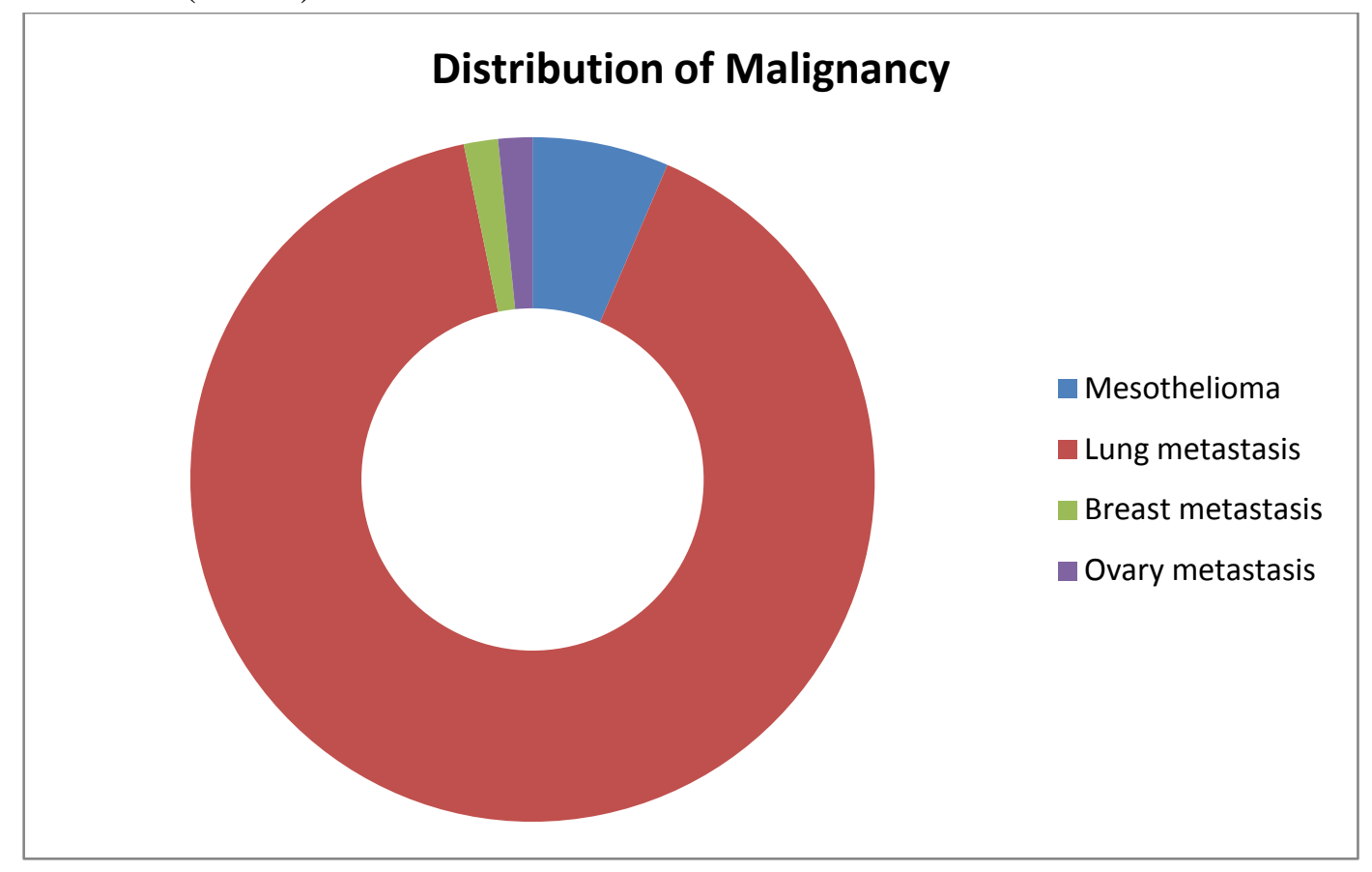

\section{Types of malignancies}

Overall diagnostic yield of thoracoscopic pleural biopsy was $100 \%$ in patients with undiagnosed pleural effusions. Pleural malignancy was diagnosed in $(73.8 \%)$ of patients. There were only four cases of mesothelioma and the rest were due to pleural metastasis. Lung was the most common site of primary malignancy and adenocarcinoma being the most common type. Tuberculosis was diagnosed with pleural biopsy in (26.2\%) patients. 


\section{Types of malignancy}
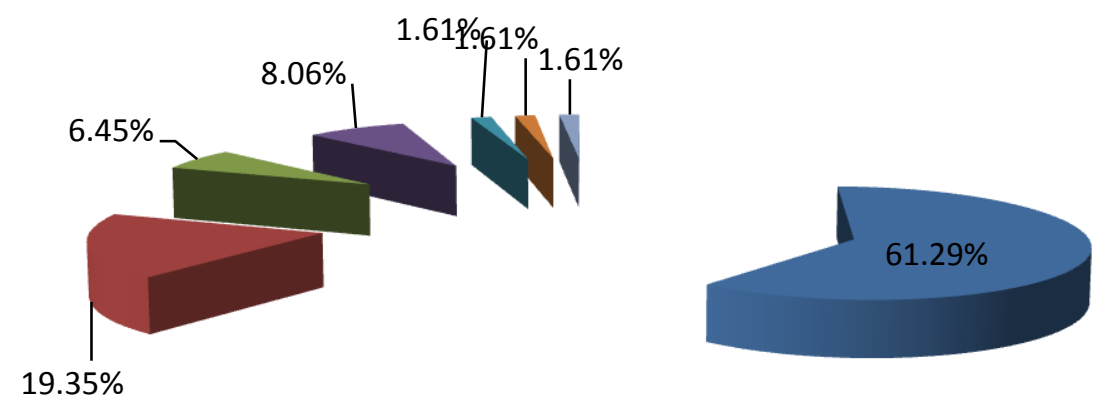

- Adenocarcinoma lung

- Mesothelioma

- Alveolar cell carcinoma

- Carcinoma ovary
- Small cell lung carcinoma

- Squamous cell carcinoma

- Breast carcinoma

\section{Complications}

There were no major complications recorded. $31 \%$ were devoid of any complications. Commonest minor complications noted were Pain $(35.7 \%)$ followed by Fever (11.9\%). 14.3\% were noted to have subcutaneous emphysema following the procedure. There were six cases $(7.1 \%)$ who had persistent air leak (>7days) after the procedure.

\section{DISCUSSION}

This study, analyzed the data of 84 patients who underwent medical thoracoscopy for the diagnosis of pleural effusions with undetermined etiolgy. Patients with undiagnosed pleural effusions with inconclusive initial diagnostic work-up(fluid analysis, fluid cytology, ADA, blind pleural biopsy) were included. The yield of thoracoscopic pleural biopsy was $100 \%(84 / 84)$ in this study.

Similar experience with medical thoracoscopy has been described from other centers. Mootha V.K et $\mathrm{al}^{27}$ from PGI Chandigarh, India, reported yield of thoracoscopic pleural biopsy to be $74.3 \%$ in their study which included 35 patients with undiagnosed pleural effusion, pleural malignancy was diagnosed in $48.6 \%$ of patients while tuberculosis was diagnosed with pleural biopsies in $22.8 \%$ of patients. Kendall et $a l^{28}$ reported yield of thoracoscopic pleural biopsy to be $83 \%$ in their study which included 48 patients. Tscheikuna et $a l^{29}$ described their experience from Thailand $(\mathrm{n}=86)$ and thoracoscopy was diagnostic in $95 \%$ of 34 patients. $\mathrm{Ng}$ et $a l^{30}$ could achieve diagnosis with thoracoscopic pleural biopsy in $45.5 \%$ $(10 / 22)$ patients with undiagnosed pleural effusions.

In this study a large proportion of patients $62 / 84$ (73.8\%) of Undiagnosed pleural effusion, had pleural malignancy followed by Tuberculosis 22/84 (26.2\%).

Similar observations were made by Mootha V.K et al from PGI Chandigarh who found Tuberculosis in $22.8 \%$ of his patients and malignancy in $48.6 \%$ of patients.

Pleural metastasis was more common cause of malignant pleural effusions than Primary pleural malignancy (mesothelioma). We had only 4 cases of mesothelioma whereas 56 of the 62 cases were due to pleural metastasis. Among the patients with metastatic pleural malignancy diagnosed with thoracoscopic pleural biopsy, the most common site of primary malignancy was the lung, and adenocarcinoma being the most common. Small 
cell lung cancer and squamous cell lung cancer were less common diagnosis. These findings are in concordance with the findings of others. $1.61 \%$ of patients, the primary site was breast and ovary. Twenty two out of $84(26.2 \%)$ patients had pleural TB on pleural biopsy. This is in stark contrast to the findings of Kendall et al who did not find any case of TB in their study of 48 patients undergoing thoracoscopy for undiagnosed pleural effusions, but similar to the findings of Mootha et al from Chandigarh who diagnosed tuberculosis in $22.8 \%$ of his patients who underwent thoracoscopy for undiagnosed pleural effusion. This is probably due to low prevalence of TB in the West and high in our country. Thoracoscopic pleural biopsy is considered gold standard in diagnosis of malignant pleural effusion and TB pleural effusion. Diagnostic yield of thoracoscopic pleural biopsy can be as high as $100 \%$ which is far superior to that of pleural fluid analysis and closed pleural biopsy. These findings suggest that thoracoscopic pleural biopsy should be considered in all patients with pleural effusions who remain undiagnosed after initial pleural fluid analysis.

A variety of complications are associated with thoracoscopy, such as subcutaneous emphysema $(0.6 \%-4.9 \%)$, air leak $(0.5 \%-8.1 \%)$, empyema $(0.5 \%-2.7 \%)$, haemorrhage $(0.3 \%-0.4 \%)$, shock $(0.2 \%)$, chest wall seeding by malignancy $(0.5 \%$ $4.0 \%) .{ }^{34-40}$ We did not have any major complications. $31 \%$ were devoid of any complications. Commonest minor complications noted were pain $(35.7 \%)$ followed by fever (11.9\%). $14.3 \%$ were noted to have S/C Emphysema following the procedure and there were six cases $(7.1 \%)$ who had persistent air leak (>7days) after the procedure.

\section{CONCLUSION}

The results of this study suggest that medical thoracoscopy is a safe procedure and should be considered in patients with undiagnosed pleural effusions especially when malignancy and TB are two main differential diagnoses.

\section{REFERENCES}

1. Broaddus VC. Fluid and solute exchange in normal physiological states. In: Textbook of Pleural Diseases, 2nd Edition, Light, RW, Lee, YGC (Eds), Hodder, Arnold, London 2008. p. 43.

2. http://www.uptodate.com/contents/diagnosticevaluation-of-a-pleural-effusion-in-adultsinitial-testing

3. Metintas M, Ak G, Dundar E, Yildirim H, Ozkan R, Kurt E, Erginel S, Alatas F, Metintas S. Medical thoracoscopy Vs CT scan-guided Abrams pleural needle biopsy for diagnosis of patients with pleural effusions: a randomized, controlled trial. Chest 2010; 137(6): 1362.

4. Gonlugur U, Gonlugur TE. J Biomed Sci. 2005;12(6):985.

5. Miura T, Shimada T, Tanaka K, Chujo M, Uchida Y. Lymphatic drainage of carbon particles injected into the pleural cavity of the monkey, as studied by video-assisted thoracoscopy and electron microscopy. J Thorac Cardiovasc Surg 2000; 120(3): 437.

6. Lai-Fook SJ. Pleural mechanics and fluid exchange: Physiol Rev. 2004;84(2):385

7. Noppen M, De Waele M, Li R, Gucht KV, D'Haese J, Gerlo E, Vincken W. Volume and cellular content of normal pleural fluid in humans examined by pleural lavage. Am J Respir Crit Care Med 2000; 162(3 Pt 1): 1023.

8. Venekamp LN, Velkeniers B, Noppen M. Respiration. 2005;72(1):74

9. Quick CM, Venugopal AM, Dongaonkar RM, Laine GA, Stewart RH. Am J Physiol Heart Circ Physiol. 2008;294(5):H2144.

10. Hosking B, Makinen T. Lymphatic vasculature: a molecular perspective. Bioessays. 2007;29(12):1192.

11. Yilmaz U, Polat G, Sahin N, Soy O, Gülay U. Monaldi Arch Chest Dis. 2005;63(1):17

12. Huggins JT, Sahn SA, Heidecker J, Ravenel JG, Doelken P. Characteristics of trapped lung: pleural fluid analysis, 
manometry, and air-contrast chest CT. Chest. 2007;131(1):206

13. Sakuraba M, Masuda K, Hebisawa A, Sagara $\mathrm{Y}$, Komatsu H. Diagnostic value of thoracoscopic pleural biopsy for pleurisy under local anaesthesia. ANZ $\mathrm{J}$ Surg. 2006;76(8):722

14. Metintas M, Ak G, Dundar E, Yildirim H, Ozkan R, Kurt E, Erginel S, Alatas F, Metintas S. Medical thoracoscopy vs CT scan-guided Abrams pleural needle biopsy for diagnosis of patients with pleural effusions: a randomized, controlled trial. Chest. 2010;137(6):1362.

15. Breen D, Fraticelli A, Greillier L, Mallawathantri S, Astoul P. Redo medical thoracoscopy is feasible in patients with pleural diseases - a series. Interact Cardiovasc Thorac Surg. 2009;8(3):330

16. Rodriguez-Panadero F, Janssen JP, Astoul P. Thoracoscopy: general overview and place in the diagnosis and management of pleural effusion. Eur Respir J 2006; 28(2): 409.

17. Michaud G, Berkowitz DM, Ernst A. Pleuroscopy for diagnosis and therapy for pleural effusions. Chest. 2010;138(5):1242

18. Breen D, Fraticelli A, Greillier L, Mallawathantri S, Astoul P. Interact Cardiovasc Thorac Surg. 2009;8(3):300.

19. Brims FJ, Arif M, Chauhan AJ. Outcomes and complications following medical thoracoscopy. Clin Respir J. 2012 Jul;6(3):144-9. Epub 2011 Aug 16.

20. Medford AR, Agrawal S, Bennett JA, Free CM, Entwisle JJ. Respirology. 2010;15(5):804

21. Ishida A, Nakamura M, Miyazawa T, Astoul P. Interact Cardiovasc Thorac Surg. 2011 May;12(5):667-70. Epub 2011 Feb 5.

22. Ernst A, Hersh CP, Herth F, Thurer R, LoCicero J 3rd, Beamis J, Mathur P. A novel instrument for the evaluation of the pleural space: an experience in 34 patients. Chest 2002; 122(5): 1530.

23. Lee P, Hsu A, Lo C, Colt HG. Prospective evaluation of flex-rigid pleuroscopy for indeterminate pleural effusion: accuracy, safety and outcome. Respirology 2007; 12(6): 881.

24. Lee P, Hsu A, Lo C, Colt HG Prospective evaluation of flex-rigid pleuroscopy for indeterminate pleural effusion: accuracy, safety and outcome. Respirology. 2007;12(6):881

25. Munavvar M, Khan MA, Edwards J, Waqaruddin Z, Mills J. The autoclavable semirigid thoracoscope: the way forward in pleural disease? Eur Respir J. 2007 Mar;29(3):571-4. Epub 2007 Jan 10.

26. Michaud G, Berkowitz DM, Ernst A. Pleuroscopy for diagnosis and therapy for pleural effusions. Chest 2010; 138(5): 1242

27. Mootha VK, Agarwal R, Singh N, Aggarwal AN, Gupta D, Jindal SK. Medical Thoracoscopy for Undiagnosed Pleural Effusions: Experience from a Tertiary Care Hospital in North India. Indian $\mathbf{J}$ Chest Dis Allied Sci 2011; 53: 21-24.

28. Kendall SW, Bryan AJ, Large SR, Wells FC. Pleural effusions: is thoracoscopy a reliable investigation? A retrospective review. Respir Med 1992; 86: 437-40.

29. Tscheikuna J, Silairatana S, Sangkeaw S, Nana A. Outcome of medical thoracoscopy. J Med Assoc Thai 2009; 92 (Suppl. 2): S19$\mathrm{S} 23$.

30. Ng TH, How SH, Kuan YC, Hasmah H, Norra H, Fauzi AR. Medical thoracoscopy: Pahang experience. Med J Malaysia 2008; 63: 298 